\title{
A CEAGESP DE PRESIDENTE PRUDENTE E A GESTÃO DOS RESÍDUOS VEGETAIS
}

\author{
Rosângela Rosa ${ }^{1}$ \\ Daniel dos Santos Viais Neto ${ }^{2}$ \\ Ari Alves de Oliveira Filho ${ }^{3}$
}

RESUMO: Uma crescente preocupação é observada no que se refere às questões ambientais e seu impacto na qualidade de vida humana, principalmente em relação ao aumento da quantidade e variedade de resíduos advindos das atividades industriais e agrícolas, os quais provocam sérios danos ao meio ambiente e à saúde pública. $O$ presente trabalho buscou coletar e quantificar dados e informações na CEAGESP Presidente Prudente, quanto ao destino final dos resíduos de vegetais impróprios para a comercialização, com a expectativa de contribuir de forma positiva para um gerenciamento da empresa. Os termos que envolvem resíduos e sistemas de desenvolvimento sustentável foram à base de discussão deste trabalho. Os resultados obtidos apontam um elevado índice de perda nas atividades que envolvem a comercialização dos produtos hortícolas, ressaltam a importância de um melhor gerenciamento desde a fase pós-colheita até o consumo final desses produtos e evidenciam a necessidade do aproveitamento dos resíduos vegetais, bem como a possibilidade de aumentar o índice de doação dos produtos excedentes.

Palavras-chave: Gestão de Resíduos, Responsabilidade Ambiental, Sustentabilidade.

\footnotetext{
1 Tecnólogo em Agronegócio, FATEC de Presidente Prudente. rosangelarosa.tecnoagro@hotmail.com.

${ }^{2}$ Licenciado e Bacharel em Matemática (ICMC/USP), Mestre em Matemática Pura (ICMC/USP), Professor Associado da FATEC - Presidente Prudente. dvneto@fatecpp.edu.br.

${ }^{3}$ Graduado em Direito (TOLEDO), Especialista em Direito Civil e Processual Civil (TOLEDO), Mestre em Direito (TOLEDO), Professor Associado da FATEC - Presidente Prudente. ari.filho@fatec.sp.gov.br.
} 


\section{INTRODUÇÃO}

As questões ambientais têm despertado cada vez mais a preocupação de todos os envolvidos em atividades industriais e agrícolas. Resíduos gerados nessas atividades causam impactos negativos, ou seja, danos ao meio ambiente se não forem tratados de maneira adequada, por exemplo, a poluição física de imensas áreas destinadas a aterros sanitários e as áreas tomadas por lixões que servem de depósito a céu aberto sem nenhuma espécie de tratamento.

As consequências dessa prática são a formação do chorume, substância tóxica proveniente da degradação do lixo que agride severamente o solo e lençóis freáticos, a degradação da paisagem, a poluição do ar, lagos e rios, e os problemas sanitários que atingem a população.

Sabe-se que o bem estar físico e psíquico está correlacionado às condições do ambiente em que se vive. Nesta perspectiva a Constituição Federal afirma que o meio ambiente ecologicamente equilibrado é essencial à saúde. No entanto, a qualidade de vida citada na Constituição Federal, não foca somente o equilíbrio ambiental, mas os benefícios em geral, que devem ser proporcionados a todos de modo coletivo por meio das atividades econômicas e obras de infraestrutura (FIORILLO, 2004).

É preciso ressaltar que não é possível abrir mão do desenvolvimento econômico do país em função da plena proteção ambiental, pois ambos estão interligados, para o equilíbrio socioeconômico do país. O correto é encontrar um equilíbrio no desenvolvimento econômico, sem coibi-lo, mas oferecendo algumas alternativas, para que haja alterações positivas e possíveis.

A proposta deste trabalho foi discutir sobre a problemática do resíduo vegetal através de um estudo de caso realizado nas dependências da CEAGESP de Presidente Prudente. Neste estudo, buscou-se coletar e quantificar dados e informações da empresa quanto ao destino final dos resíduos de vegetais impróprios para a comercialização, com a expectativa de que esse estudo possa contribuir na gestão e no gerenciamento destes 
resíduos, defendendo o conceito de sustentabilidade e sua importância dentro das atividades que promovem o desenvolvimento da região.

\section{MATERIAIS E MÉTODOS}

\subsection{Materiais}

A presente pesquisa foi delineada como um estudo de caso, do tipo exploratório na unidade da CEAGESP que está localizada na Av. Juscelino Kubitschek de Oliveira, $\mathrm{n}^{\circ}$ 105, Jardim dos Jequitibás em Presidente Prudente - SP (Figura 1).

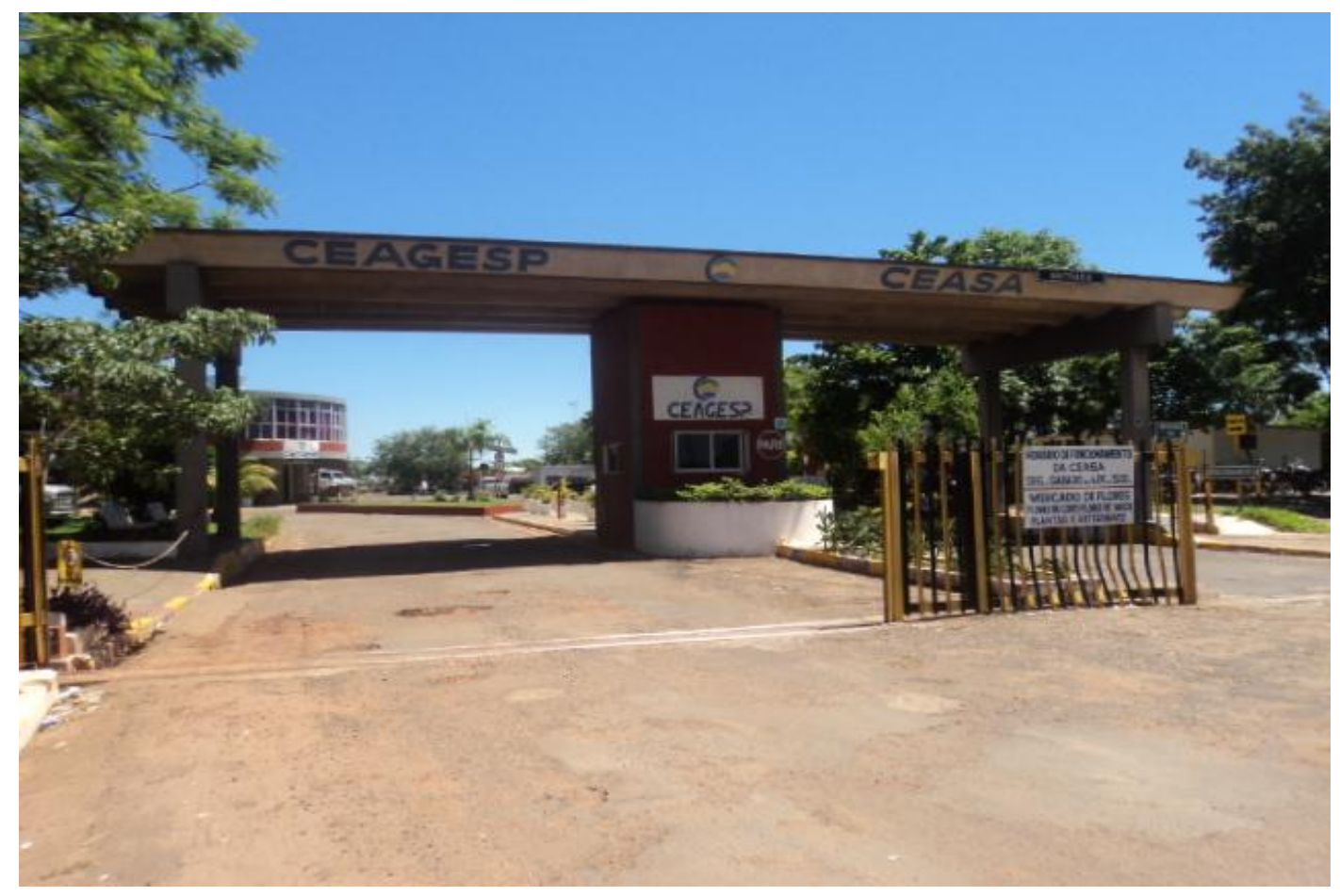

Figura 1. A CEAGESP de Presidente Prudente. Fonte: Pesquisa de Campo.

Foi empregado um GPS para calcular com precisão a área onde se realizou a coleta de dados. A Figura 2 representa a área destinada à comercialização e inclui a parte interna do entreposto, as plataformas, rampas de acesso, estacionamentos, boxes e as outras construções. A área total é de $9.274,4 \mathrm{~m}^{2}$. 
Foi utilizado o software Microsoft Excel 2007 para a análise dos dados.

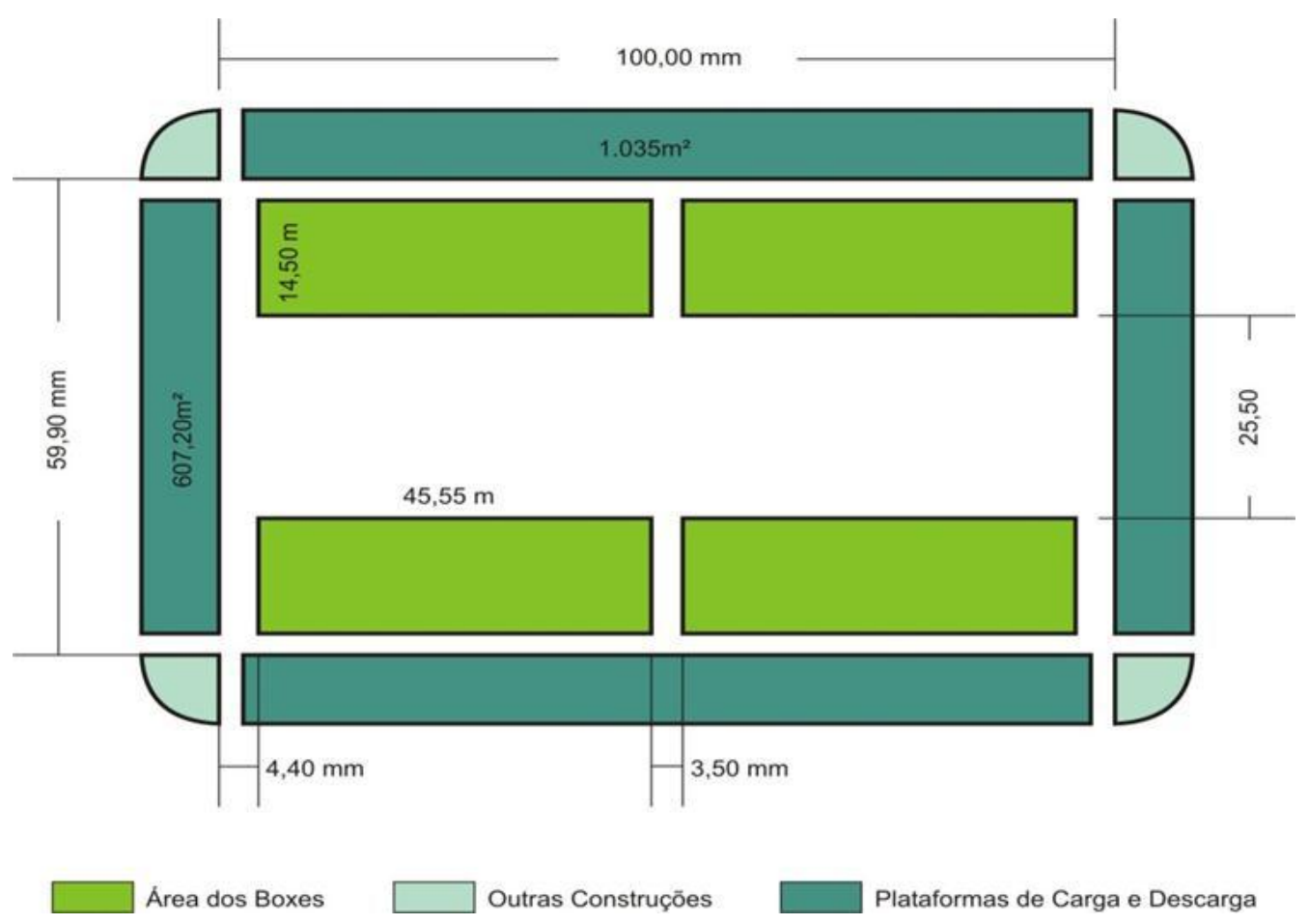

Figura 2. Croqui da área de comercialização da CEAGESP de Presidente Prudente. Fonte: Pesquisa de Campo.

\subsection{Métodos}

As amostras de resíduos vegetais utilizadas neste trabalho são do tipo NãoAleatória, ou seja, aquela em que os membros mais acessíveis da população são selecionados de maneira à rapidamente obter os resultados (MANN, 2006).

Os dados foram coletados no mês de julho de dois mil e onze (07/2011). E com base em informações fornecidas pela empresa, A metade desta coleta foi realizada em dias de maior movimentação (entrada e comercialização de produtos), que são os primeiros doze dias de cada mês. A outra metade, em dias de menor movimentação. Ao total, foram realizadas 12 coletas, como mostra a Figura 3. 


\begin{tabular}{|c|c|c|c|c|c|c|}
\hline \multicolumn{7}{|c|}{ JULHO 2011} \\
\hline Domingo & Segunda-feira & Terça-feira & Quarta-feira & Quinta-feira & Sexta-feira & Sábado \\
\hline & & & & & 1 & 2 \\
\hline 3 & 4 & 5 & 6 & 7 & 8 & 9 \\
\hline 10 & 11 & 12 & 13 & 14 & 15 & 16 \\
\hline 17 & 18 & 19 & 20 & 21 & 22 & 23 \\
\hline 24 & 25 & 26 & 27 & 28 & 29 & 30 \\
\hline 31 & & & & & & \\
\hline
\end{tabular}

Dias de maior movimentação

Dias de menor movimentação

Dias sem atividade

Figura 3. Cronograma de coleta de dados. Fonte: Elaborado pelos autores.

Para obtenção do volume de perda diária de vegetais, nos dias de coleta todos os resíduos foram recolhidos e pesados. Entretanto, antes da pesagem, os resíduos passaram por uma triagem. Nesta triagem, os resíduos vegetais eram separados dos demais resíduos que possuem outras características, como por exemplo, plástico, papelão, alumínio e madeira, ou seja, resíduos que acabam se juntando aos rejeitos vegetais na área de movimentação de cargas e também na parte interna onde ocorre a distribuição dos produtos entre os boxes, para a comercialização. Estão incluídos também nesta contagem os vegetais que são desprezados pelos comerciantes que geralmente são depositados nos latões que se encontram dentro da área interna e próximos às plataformas. As Figuras 4 e 5, respectivamente, demostram o momento da triagem e pesagem, que em geral ocorria durante a varrição do local.

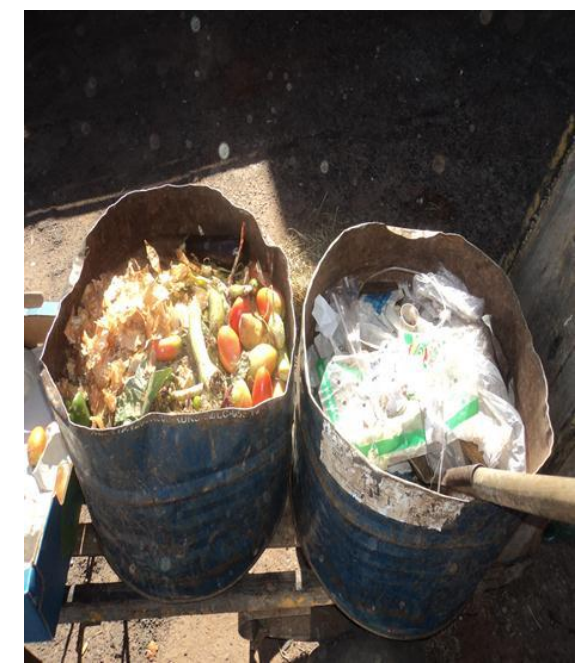

Figura 4. Triagem dos Resíduos. Fonte: Pesquisa de Campo. 


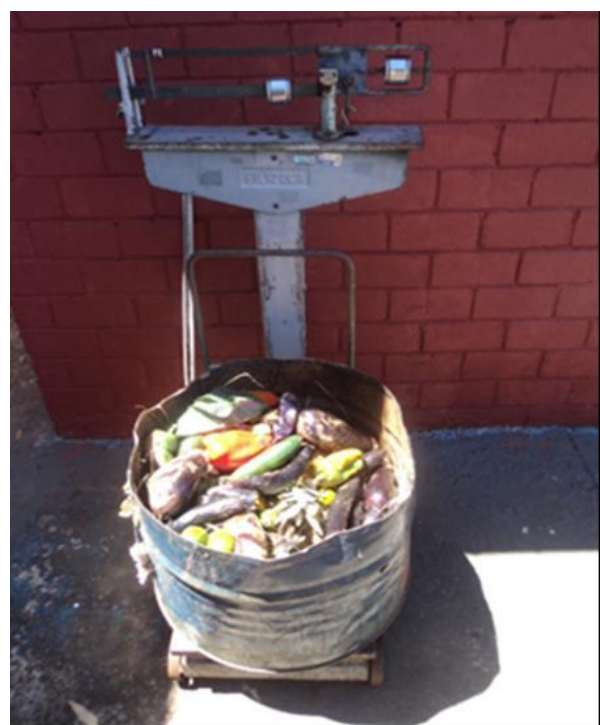

Figura 5. Pesagem dos Resíduos. Fonte: Pesquisa de Campo.

\section{RESULTADOS E DISCUSSÃO}

\subsection{Apresentação dos dados coletados}

No mês de julho de dois mil e onze, mês em que foram coletados os dados, na CEAGESP de Presidente Prudente, o volume comercializado de produtos foi de 3.883 toneladas e o volume de doações foi de $17.293 \mathrm{~kg}$. Já o total de resíduos gerados nesta empresa durante o mesmo período foi de $17.095 \mathrm{~kg}$ (Tabela 1).

Tabela 1. Totais de Resíduos gerados na CEAGESP de Presidente Prudente no mês de Julho de 2011.

\begin{tabular}{lrlr}
\hline Primeiro grupo de a mostras & \multicolumn{2}{l}{ Segundo grupo de amostras } \\
\hline Dias de maior movimentação & Peso kg & Dias de menor movimentação & Peso kg \\
\hline 04/jul & $1.372,0$ & $18 / \mathrm{jul}$ & 815,0 \\
$06 / \mathrm{jul}$ & $1.140,0$ & $20 / \mathrm{jul}$ & $1.572,0$ \\
$07 / \mathrm{jul}$ & $1.147,0$ & $22 / \mathrm{jul}$ & $1.504,0$ \\
$08 / \mathrm{jul}$ & $1.615,0$ & $26 / \mathrm{jul}$ & $1.971,0$ \\
$09 / \mathrm{jul}$ & $1.658,0$ & $28 / \mathrm{jul}$ & $1.663,0$ \\
12/jul & $1.692,0$ & $30 / \mathrm{jul}$ & 946,0 \\
\hline Totais & $\mathbf{8 . 6 2 4 , 0}$ & $\mathbf{8 . 4 7 1 , 0}$ \\
\hline Mé dias & $\mathbf{1 . 4 3 7 , 3}$ & $\mathbf{1 . 4 1 1 , 8}$ \\
\hline Desvios padrão & $\mathbf{2 5 3 , 8}$ & $\mathbf{4 4 3 , 4}$ \\
\hline
\end{tabular}

Fonte: Pesquisa de Campo. 
A partir dos resultados apresentados na Tabela 1 foi possível obter a média da perda diária do mês de julho, bem como a mediana e o desvio padrão, como mostra a Tabela 2.

Tabela 2. Estimativa de Perda de Vegetais no Mês de Julho de 2011.

\begin{tabular}{lr}
\hline \multicolumn{2}{c}{ Índices re ferente ao mês de julho/2011 } \\
\hline Média & Peso kg/dia \\
Mediana & $1.424,6$ \\
Desvio padrão & $1.538,0$ \\
\hline
\end{tabular}

Fonte: Pesquisa de Campo.

De acordo com a média da perda diária obtida e considerando os vinte e seis dias úteis do mês em questão, o total mensal de resíduos vegetais chega a $37.039,2 \mathrm{~kg}$. Este valor representa aproximadamente $1,1 \%$ do volume de entrada de produtos. Caso este percentual se confirme em outros meses do ano o desperdício anual pode chegar a $444.470,4 \mathrm{~kg}$ de hortifrútis. Entretanto não seria viável fixar este valor anual, pois o comércio de hortifrútis é caracterizado por períodos de sazonalidade de produtos e o mês de julho é marcado por baixas temperaturas, fato que influencia diretamente nos hábitos de consumo da população, ou seja, o volume da perda de vegetais pode ser ainda mais expressivo nos meses de temperaturas mais elevadas e meses festivos (dezembro, por exemplo) onde segundo a empresa, a comércio de frutas e hortaliças é maior.

Outros fatores que foram observados na pesquisa de campo estão relacionados com a perda de produtos hortifrútis, entre eles as deficiências operacionais, a temperatura, a embalagem e o transporte desses produtos.

A empresa afirma que as perdas de produtos também estão relacionadas com a movimentação do comércio, datas próximas a vencimentos mensais favorecem as atividades com maior poder de compra e venda, e consequentemente aumenta a produção de resíduos vegetais; e nos dias de menor movimentação comercial, aumenta a produção de resíduos devido à falta de giro dos produtos. 


\subsection{Destino dos resíduos vegetais}

Segundo uma das atribuições citadas na Lei Estadual dos Resíduos Sólidos 12300/06, Cap. III, Artigo $5^{\circ}$ Inciso III, o município deverá promover a minimização dos resíduos gerados: a redução, ao menor volume, quantidade e periculosidade possíveis, dos materiais e substâncias, antes de descartá-los no meio ambiente.

Foi divulgado pela CETESB no Inventário Estadual de Resíduos Sólidos Domiciliares de 2010, que o município de Presidente Prudente, produziu em 2010, 122 toneladas/dia de Resíduo Urbano, e está enquadrado como inadequado quanto à disposição e tratamento de resíduos sólidos domiciliares (CETESB, 2010).

A empresa retira em média duas a três caçambas de lixo por dia, executado por meio de terceirização do serviço, uma vez que a Prefeitura Municipal não realiza a coleta, e esses resíduos são direcionados ao lixão da cidade.

Existem perspectivas da empresa em conseguir parcerias para que esses resíduos orgânicos sejam aproveitados através da compostagem. Para tanto é necessário local apropriado para armazenamento dos resíduos antes que estes sejam compostados. No entanto, uma parceria com algum órgão público da cidade seria promissor, uma vez que o composto orgânico pode ser utilizado para a recuperação de áreas urbanas como praças e logradouros e adubação da horta municipal. Entidades sociais desta cidade poderiam ser beneficiadas com a doação do fertilizante orgânico, pois estas desenvolvem trabalhos terapêuticos com atividades agrícolas envolvendo pessoas portadoras de necessidades especiais, e a produção dessas hortaliças geralmente é para consumo próprio.

\subsection{Os resíduos que apresentam outra característica física}

Os resíduos pertencentes às outras classes podem ser separados e reciclados. A proposta é que a separação seja feita com a colaboração de funcionários responsáveis pela manutenção e limpeza do local durante a varrição, e como incentivo todo o material reciclável pode ser vendido e a receita gerada dividida entre os colaboradores. Essas mudanças são simples e podem ser implantadas com sucesso, uma vez que a separação 
do lixo já é hábito em escolas, universidades, praças, shopping centers, e outros locais com grande movimentação de pessoas.

Devem-se observar algumas precauções importantes quanto ao material reciclável, que deve ser acondicionado em local apropriado para que não ocasione acidentes ou sirva de atrativo de insetos e roedores.

Outra medida também poderá ser adotada no processo de separação é a sinalização dos latões existentes no interior do galpão. Estes devem ser pintados correspondendo à cor que caracteriza a origem do lixo, priorizando o número de latões direcionados aos de origem orgânica por representarem maior quantidade. Além disso, a empresa poderá solicitar vínculos com empresas dispostas a financiar a compra e pintura dos latões, e os custos seriam praticamente nulos.

Esta prática está presente em uma resolução do CONAMA, Ementa 275/01 que estabelece o código de cores para os diferentes tipos de resíduos, a ser adotado na identificação de coletores e transportadores, bem como nas campanhas informativas para a coleta seletiva.

\section{CONCLUSÃO}

Manter satisfatória a gestão de resíduos, de forma geral é uma tarefa extremamente difícil, seja por razões sociais ou falhas nas etapas de gerenciamento, e principalmente por não haver limitações na sua geração, fator determinante quanto volume e inconvenientes relacionados ao resíduo.

Do montante de resíduos coletados na CEAGESP, foi possível identificar que, diariamente perde-se uma quantidade significativa de resíduos de origem vegetal e de outras características físicas, todos com possibilidade de aproveitamento.

Durante o desenvolvimento da pesquisa de campo foram discutidas ideias relacionadas à diminuição do lixo nas dependências da empresa. Inicialmente, a procura por parcerias possibilitaria uma ação conjunta e promoveria ações de cidadania e preservação ao meio ambiente, fator que resultaria em destinação adequada e diminuição do volume dos resíduos da CEAGESP. 
Mudanças também proporcionam interesse de outros pesquisadores, mídia e também da população, uma vez que a transformação no panorama da gestão do resíduo não depende somente da ação pública, acontece em parceria com a comunidade, sendo em empresas ou locais abertos.

\section{REFERÊNCIAS}

CETESB - COMPANHIA AMBIENTAL DO ESTADO DE SÃO PAULO. Inventario Estadual de Resíduos Sólidos Domiciliares. São Paulo, 2010.

FIORILLO, C. A. P. Curso de Direito Ambiental Brasileiro. $5^{\mathrm{a}}$ ed. Saraiva. São Paulo, 2004.

MANN. P.S. Introdução a Estatística. 5ª ed. LTC. Rio de Janeiro. 2006. 